\title{
Comparing the effect of adding dexmedetomidine and tramadol to lidocaine $5 \%$ in elongating the period of post-operative analgesia in spinal anesthesia.
}

\author{
Alireza Kamali ${ }^{1}$, Maryam Shokrpour ${ }^{2 *}$, Aminlu Radmehr ${ }^{3}$, Shirin Pazuki ${ }^{1}$ \\ ${ }^{1}$ Department of Anesthesiology, Arak University of Medical Sciences, Arak, Iran \\ ${ }^{2}$ Department of Gynecology, Arak University of Medical Sciences, Arak, Iran \\ ${ }^{3}$ Medical Student, Arak University of Medical Sciences, Arak, Iran
}

\begin{abstract}
Background: The aim of this study was to compare addition of dexmedetomidine and tramadol to lidocaine $5 \%$ in the period of postoperative analgesia of spinal anesthesia among women candidated for caesarean.

Methods: This double-blind clinical trial conducted on women applying for elective caesarean. Two hundred and ten women were participated in this research and they randomly divided into dexmedetomidine, tramadol and placebo groups. The pain scale, length of analgesia and the average amount of the drug taken within $24 \mathrm{~h}$, after postoperative nausea, vomiting and shivering measured.

Results: No significant difference was observed among the two gropus on pain score, length of postoperative analgesia, the amount of drug, postoperative nausea, vomiting and shivering $(P \geq 0.05)$.

Conclusion: Taken together, dexmedetomidine and tramadol were beneficial compared to the placebo. Therefore it may be utilized to reduce pain in caesareans.
\end{abstract}

Keywords: Spinal, Tramadol, Dexmedetomidine, Caesarean.

Accepted on December 08, 2017

\section{Introduction}

Caesarean is one of the most common types of gynecological operations. Controlling postoperative pain is one of the most important issues of operation that affects the healthcare system. Postoperative pain will delay patient's return to normal conditions, elongate the hospitalization period, increase occurrence of atelectasis, venous thrombosis, and patients' dissatisfaction. Prescription of analgesics in postoperative period improves the patients' pain and consequently results in improved pulmonary performance due to facilitation of physiotherapy by the patient. As the patient resumes his normal activities much faster, the result will be less constipation, less venous thromboembolic complications, and shorter period of restoration [1]. Narcotic analgesics used as strong pain killers after operation are associated with various complications and side effects such as dizziness, reduced pulmonary performance, ileus, nausea, vomiting, itching, and urinary retention. Controlling the patient's pain requires periodic venous and intramuscular injections so that the medicine may reach a stable state that is always more than the minimum effective anesthetics concentration. However, insufficient and unpredictable blood densities in injection intervals make determination of the appropriate dose and adjusting the medicine to the stable density difficult. As a result, an accurate nursing car will be required to prevent the venous injection of a high amount of medicine that is associated with high prevalence of central nervous system and respiratory system weakening. In most cases drugs given upon the request of the patient, the sufficient level of analgesia is never achieved. Painkillers without the above-said complications, which have a better and more enduring analgesic effect, are preferable [2].

Due to analgesic properties and lack of harmful effects in contrast to opioids, local anesthetics largely used to treat surgical pain. If the acute pain is not controlled and managed properly, it may have adverse effects on various systems of the body including inability to discharge mucosa from the respiratory system, digestive system ileus, high heart beat and blood pressure, sweating, going pale, longer period of resting in bed, higher risk of deep venous thrombosis, and delayed milking onset [3]. As a result, finding a medicine, which can have the longest period of postoperative analgesia, is one of the most important issues after caesarean. To reduce patient's pain, various medicines such as drugs and other non-narcotic painkillers are used. Non-narcotic drugs have several advantages over their narcotic counterparts including no respiratory weakness, no potential of drug abuse, less stupefying effects, less nausea, early restoration of intestinal performance, and quicker recovery. Considering these potential advantages, many doctors prefer non-narcotic painkillers $[4,5]$. The goal of this study was to evaluate of addition of 
dexmedetomidine and tramadol to lidocaine 5\% in elongating the length of post-caesarian analgesia in spinal anesthesia.

\section{Materials and Methods}

This is a randomized, double blind clinical trial conducted on women aging 20 to 40 years old with class I or II ASA applying for elective caesarean. With proposal of the research approved by the ethics committee of Ark University of Medical Sciences, 108 signed the consent form and took part in the research. The participants were randomly divided into 3 groups: 1) tramadol with lidocaine $5 \%, 2$ ) dexmedetomidine with lidocaine $5 \%$, and 3 ) control groups. No affliction with chronic disease such as cardiovascular, liver and renal disease and no allergy to local anesthetics were the inclusion criteria defined for the research, while a history of drug abuse, failure of spinal anesthesia, more than 2 attempts to achieve spinal anesthesia, and operations lasting longer than 90 min were the exclusion criteria. In the beginning of the research, all patients received 3-5 $\mathrm{mL} / \mathrm{kg}$ of body weight crystalloid as the alternative liquid for vasodilatation.

Table 1. Information of research variables.

\begin{tabular}{|c|c|c|c|c|c|c|c|c|c|c|c|c|c|}
\hline \multirow{3}{*}{ Name } & \multirow{3}{*}{$\begin{array}{l}\text { Definiti } \\
\text { on } \\
\text { (scientif } \\
\text { ic and } \\
\text { applied) }\end{array}$} & \multicolumn{7}{|c|}{ Type of variable } & \multicolumn{4}{|c|}{ Scale of variable } & \multirow{3}{*}{$\begin{array}{l}\text { Variable } \\
\text { measurem } \\
\text { ent unit }\end{array}$} \\
\hline & & \multicolumn{4}{|c|}{ Based on research goals } & \multicolumn{3}{|c|}{ Based on the type of variable } & \multicolumn{2}{|c|}{ Qualitative } & \multicolumn{2}{|c|}{ Quantitative } & \\
\hline & & $\begin{array}{l}\text { Independe } \\
\text { nt }\end{array}$ & $\begin{array}{l}\text { Depende } \\
\text { nt }\end{array}$ & $\begin{array}{l}\text { Contextu } \\
\text { al }\end{array}$ & $\begin{array}{l}\text { Interfere } \\
r\end{array}$ & $\begin{array}{l}\text { Discretely } \\
\text { quantitativ } \\
\text { e }\end{array}$ & $\begin{array}{l}\text { Continuousl } \\
\text { y } \\
\text { quantitative }\end{array}$ & $\begin{array}{l}\text { Qualitativ } \\
\mathrm{e}\end{array}$ & $\begin{array}{l}\text { Nomin } \\
\text { al }\end{array}$ & $\begin{array}{l}\text { Rankin } \\
\text { g }\end{array}$ & $\begin{array}{l}\text { Interva } \\
\text { I }\end{array}$ & $\begin{array}{l}\text { Proportion } \\
\text { al }\end{array}$ & \\
\hline $\begin{array}{l}\text { Being placed in } \\
\text { Dexmedetomidin } \\
\mathrm{e}, \text { tramadol and } \\
\text { control group }\end{array}$ & & * & & & & & & * & & & & & $\begin{array}{l}\text { Three } \\
\text { groups of } \\
D, T \text {, and } P\end{array}$ \\
\hline $\begin{array}{l}\text { The average } \\
\text { length of } \\
\text { analgesia }\end{array}$ & & & * & & & & * & & & & & * & Minutes \\
\hline $\begin{array}{l}\text { Average pain } \\
\text { score } \\
\text { recovery, } 4,12, \\
\text { and } 24 \mathrm{~h} \text { after } \\
\text { operation }\end{array}$ & & & * & & & & & * & & * & & & $\begin{array}{l}\text { VAS } \\
\text { questionnai } \\
\text { re }\end{array}$ \\
\hline $\begin{array}{l}\text { Average amount } \\
\text { of the analgesics } \\
\text { taken within the } \\
\text { first } 24 \mathrm{~h} \text { after } \\
\text { operation }\end{array}$ & & & * & & & & * & & & & & * & milligram \\
\hline Age & & & & * & & * & & & & & & * & Years \\
\hline
\end{tabular}

The patients were divided into three groups using the randomized umbers table. Then, they underwent spinal anesthesia in sitting position by assistant resident using No. 25 spinal anesthesia needle through lumbar space 4 and 5 or S1L5 in completely sterilized conditions utilizing 75 milligram hyperbaric lidocaine (lidocaine $5 \%$ made by Rion Pharaca with the production number: 1295235). The first group was given 25 milligram tramadol (approximately equal to $0.5 \mathrm{~mL}$ ), the second group was given 25 milligram Dexmedetomidine (approximately equal to $0.5 \mathrm{~mL}$ ), and the control group received $0.5 \mathrm{~mL}$ normal saline. As much as $2 \mathrm{~mL}$ of the solution was injected to intrathecal space. After $5 \mathrm{~min}$ and when the level of anesthesia reached No. 4 thoracic vertebrae, the procedure of operation began. During the operation, the patient was given oxygen through the mask with a flow of 5-6 $\mathrm{L} / \mathrm{min}$ and the vital signals, blood pressure, heart beat rate, and the level of venous blood oxygen saturation were measured and recorded. The patients in these three groups were assessed based upon VAS in recovery, 4,12 , and $24 \mathrm{~h}$ following the operation and the average amount of the painkiller requested within the first $24 \mathrm{~h}$ was recorded in patients' checklist. This was a double blind research where the patient, assistant resident responsible for spinal anesthesia and recording patient symptoms and the nurse responsible for determining the pain level and average painkiller used were blind.

Table 2. Comparing the pain score of patients candidated for caesarean using spinal anesthesia in recovery, 4, 12, and $24 \mathrm{~h}$ after operation in all groups.

\begin{tabular}{|c|c|c|c|c|}
\hline Time & Tramadol & Dexmedetomidine & Placebo & P-value \\
\hline Recovery & $0.28 \pm 0.16$ & $0.33 \pm 0.24$ & $2.1 \pm 2.28$ & 0.01 \\
\hline $\begin{array}{ll}4 & \text { hours } \\
\text { following } & \text { the } \\
\text { operation }\end{array}$ & $2.66 \pm 1.07$ & $2.42 \pm 1.64$ & $5.08 \pm 1.68$ & 0.001 \\
\hline $\begin{array}{l}12 \text { hours } \\
\text { following the } \\
\text { operation }\end{array}$ & $1.85 \pm 0.98$ & $2.01 \pm 1.21$ & $3.1 \pm 1.17$ & 0.02 \\
\hline
\end{tabular}




$24 \quad$ hours
$\begin{aligned} & 24 \\ & \text { following the } \\ & \text { operation }\end{aligned}$

Table 3. Comparing the average length of postoperative analgesia among patients candidated for caesarean with spinal method in all groups.

\begin{tabular}{lllll}
\hline Time & Tramadol & Dexmedetomidine & Placebo & P-value \\
\hline $\begin{array}{l}\text { Average } \\
\text { length } \\
\begin{array}{l}\text { analgesia } \\
\text { (minutes) }\end{array}\end{array}$ & $170.4 \pm 28.19$ & $172.31 \pm 2.1$ & $103.8 \pm 23.1$ & 0.01 \\
\hline
\end{tabular}

\section{Inclusion criteria:}

- All women aging 20 to 40 years candidated for elective caesarean resorting to Taleghani Hospital of Arak.

- Class I and II ASA

- No allergy to lidocaine, Dexmedetomidine, and tramadol

- Informed consent to take part in the research

\section{Exclusion criteria:}

- Patient's refusal to take part in the research

- Aging out of the range of 20 to 40 years old

- Class III and IV ASA

- Failure of spinal anesthesia

- More than 2 attempts for spinal anesthesia

- Operations lasting longer than $90 \mathrm{~min}$

- Patients with a history of drug abuse

- Patients with cardiovascular, liver or renal complications

\section{Sampling method}

Women aging 20 to 40 years old resorting to Taleghani Hospital for elective caesarean with class I and II ASA constituted the research population (Table 1).

Calculating the sample size and its number:

Based upon the following formula, the sample size was set to 108 people.

$n_{1}=n_{2}=n_{3}=\frac{\left(z_{1-\alpha / 2}+z_{1-\beta}\right)^{2}\left(\delta_{1}+\delta_{2}\right)^{2}}{\left(\mu_{1}-\mu_{2}\right)^{2}}=36$

$Z_{1-\alpha / 2}=1.96$

$Z_{1-\beta}=2.33$

$\delta_{1}=6.26$

$\delta_{2}=6.93$

$\mu_{1}=259.26$

$\mu_{2}=268.63$

\section{Results}

This is a randomized double-blind clinical trial conducted on 108 patients resorting to Taleghani Hospital of Arak for elective caesarean. According to table 2, a significant difference was observed between the pain score in Dexmedetomidine, tramadol and placebo groups in recovery and 4,12 , and $24 \mathrm{~h}$ following the operation with the pain scores in dexmedetomidine and tramadol groups being more than placebo $(\mathrm{P}=0.01, \mathrm{P}=0.001)$. However, no significant difference was observed between dexmedetomidine and tramadol groups $(\mathrm{P} \geq 0.05)$.

Table 4. A comparison of the average amount of drug taken within 24 hours following operation among patients candidated for caesarean with spinal anesthesia in all groups.

\begin{tabular}{lllll}
\hline Groups & Tramadol & Dexmedetomidine & Placebo & P-value \\
\hline $\begin{array}{l}\text { Average } \\
\begin{array}{l}\text { amount of drug } \\
\text { taken }\end{array}\end{array} \quad$ (in \\
milligrams)
\end{tabular}

Table 5. Comparing the average blood pressure of patients candidated for caesarean using spinal anesthesia in all groups.

\begin{tabular}{lllll}
\hline Groups & Tramadol & Dexmedetomidine & Placebo & P-value \\
\hline $\begin{array}{l}\text { Average blood } \\
\text { pressure before } \\
\text { operation }\end{array}$ & $69.9 \pm 11.4$ & $70.1 \pm 9.9$ & $68.7 \pm 10.2$ & $\geq 0.05$ \\
\hline $\begin{array}{l}\text { Average blood } 63.7 \pm 7.8 \\
\text { pressure } \\
\text { immediately after } \\
\text { spinal } \\
\text { anesthesia }\end{array}$ & $62.5 \pm 10.1$ & $60.9 \pm 5.8$ & $\geq 0.05$ \\
\hline $\begin{array}{l}\text { Average blood } 72.7 \pm 8.9 \\
\text { pressure } 15 \text { min } \\
\text { after } \\
\text { anesthesia }\end{array}$ & $73.5 \pm 9.8$ & & \\
\hline $\begin{array}{l}\text { Average blood } \\
\text { pressure } 30 \text { min } \\
\text { after } \\
\text { anesthesia spinal }\end{array}$ & & & & \\
\hline
\end{tabular}

Table 6. Comparing the average heart rate of patients candidated for caesarean using spinal anesthesia in all groups.

\begin{tabular}{lllll}
\hline Groups & Tramadol & Dexmedetomidine & Placebo & P-value \\
\hline $\begin{array}{l}\text { Average heart } \\
\text { rate } \\
\text { operation }\end{array}$ & $90.9 \pm 14.9$ & $91.6 \pm 7.9$ & $91.6 \pm 1.7$ & $\geq 0.05$ \\
\hline $\begin{array}{l}\text { Average heart } \\
\text { rate immediately } \\
\text { after spinal } \\
\text { anesthesia }\end{array}$ & $75.8 \pm 8.3$ & & \\
\hline $\begin{array}{l}\text { Average heart } 84.1 \pm 9.8 \\
\text { rate } 15 \text { min after } \\
\text { spinal anesthesia }\end{array}$ & $82.4 \pm 8.8$ & $76.9 \pm 1.9$ & $\geq 0.05$ \\
\hline
\end{tabular}




Average heart $87.3 \pm 9.8 \quad 85.7 \pm 6.8$
rate 30 min after
spinal anesthesia

As $\mathrm{p}$-value $=0.01$, a significant difference was observed between the three groups in terms of the average length of analgesia. The average length of postoperative analgesia in placebo group was longer than what was observed in dexmedetomidine and tramadol groups. No significant difference was observed between Dexmedetomidine and tramadol groups $(\mathrm{P} \geq 0.05$ ) (Table 3 ). As $\mathrm{p}$-value $=0.01$, a significant difference was observed between the three groups in terms of the average amount of drugs taken within $24 \mathrm{~h}$ after operation. The average amount of drug taken in placebo group more than what was observed in dexmedetomidine and tramadol groups. However, no significant difference was observed in terms of the average amount of drug taken in Dexmedetomidine and tramadol groups $(\mathrm{P} \geq 0.05)$ (Table 4).

According to Table 5, no significant difference was observed between the three groups in terms of average blood pressure in various times (before spinal anesthesia, immediately after spinal anesthesia, $15 \mathrm{~min}$ after spinal anesthesia, and $30 \mathrm{~min}$ after spinal anesthesia) $(\mathrm{P} \geq 0.05)$. According to Table 6 , no significant difference was observed between the three groups in terms of average heart rate in various times (before spinal anesthesia, immediately after spinal anesthesia, $15 \mathrm{~min}$ after spinal anesthesia, and $30 \mathrm{~min}$ after spinal anesthesia) $(\mathrm{P} \geq$ 0.05 ). As $P \geq 0.05$, no significant difference was observed between the three groups in terms of their average age and their average age was nearly equal to 25 years $(\mathrm{P} \geq 0.05)$ (Table 7). As $P \geq 0.05$, no significant difference was observed between the three groups in terms of their average age of pregnancy and the average age was nearly equal to 39 weeks (Table 8).

Table 7. Comparing the average age of the patients candidated for caesarean in all groups.

\begin{tabular}{lllll}
\hline Average age & Tramadol & Dexmedetomidine & Placebo & P-value \\
\hline $\begin{array}{l}\text { Average age of } \\
\text { patients (years) }\end{array}$ & $25.8 \pm 5.7$ & $26.1 \pm 6.6$ & $25.4 \pm 7.4$ & $\geq 0.05$ \\
\hline
\end{tabular}

Table 8. The average pregnancy age of patients candidated for caesarean in all groups.

\begin{tabular}{lllll}
\hline $\begin{array}{l}\text { Group } \\
\text { Average age }\end{array}$ & Tramadol & Dexmedetomidine & Placebo & P-value \\
\hline $\begin{array}{l}\text { Average age of } \\
\begin{array}{l}\text { pregnancy } \\
\text { (weeks) }\end{array}\end{array}$ & $39.2 \pm 7.7$ & $39.5 \pm 7.8$ & $38.9 \pm 5.6$ & $\geq 0.05$ \\
\hline
\end{tabular}

Table 9. Frequency distribution of shivering and nausea vomiting among patients candidate for caesarean using spinal anesthesia in recovery for all groups.

Groups Tramadol Dexmedetomidine Placebo P-value

\begin{tabular}{|c|c|c|c|c|}
\hline $\begin{array}{l}\text { Frequency of } \\
\text { nausea-vomiting } \\
\text { in recovery }\end{array}$ & $0.03 \%$ & $0 \%$ & $0.06 \%$ & $\geq 0.05$ \\
\hline $\begin{array}{l}\text { Frequency of } \\
\text { postoperative } \\
\text { shivering }\end{array}$ & f $0.06 \%$ & $0.06 \%$ & $0.36 \%$ & 0.01 \\
\hline
\end{tabular}

According to Table 9, no significant difference was observed between the two groups in terms of the frequency of postoperative nausea-vomiting $(\mathrm{P} \geq 0.05)$. However, a significant difference was observed between the three groups in terms of postoperative shivering with a higher frequency of shivering observed in placebo group $(\mathrm{P}=0.001)$. No significant difference was observed between tramadol and dexmedetomidine groups $(\mathrm{P} \geq 0.05)$.

\section{Discussion}

In the current study, our data showed that significant difference was observed between the three groups on terms of pain score in recovery, 4, 12 and $24 \mathrm{~h}$ following the operation with the pain score being more in dexmedetomidine and tramadol groups ( $\mathrm{P}=0.01, \mathrm{P}=0.001)$, but no significant difference was observed between dexmedetomidine and tramadol groups $(\mathrm{P} \geq$ 0.05 ). As $p$-value $=0.01$, a significant difference was observed between the three groups in terms of the average length of analgesia. The average length of postoperative analgesia in placebo group was shorter than dexmedetomidine and tramadol groups. No significant difference was observed between dexmedetomidine and tramadol groups $(\mathrm{P} \geq 0.05)$. As $\mathrm{p}$ value $=0.01$, a significant difference was observed between the three groups on terms of the average amount of drugs taken within $24 \mathrm{~h}$ after operation. The average of drug taken in placebo group was more than Dexmedetomidine and tramadol groups. However, no significant difference was observed in terms of the average amount of drug taken in dexmedetomidine and tramadol groups $(P \geq 0.05)$. No significant difference was observed between the three groups in terms of average blood pressure in various times (before spinal anesthesia, immediately after spinal anesthesia, $15 \mathrm{~min}$ after spinal anesthesia, and $30 \mathrm{~min}$ after spinal anesthesia) $(\mathrm{P} \geq 0.05)$. No significant difference was observed between the three groups in terms of average heart rate in various times (before spinal anesthesia, immediately after spinal anesthesia, $15 \mathrm{~min}$ after spinal anesthesia, and 30 min after spinal anesthesia) ( $\mathrm{P} \geq$ 0.05 ). As $P \geq 0.05$, no significant difference was observed between the three groups in terms of their average age and their average age was nearly equal to 25 years $(P \geq 0.05)$. As $P$ $\geq 0.05$, no significant difference was seen between the three groups in terms of their average age of pregnancy and the average age was nearly equal to 39 weeks.

No significant difference was found between the two groups in terms of the frequency of postoperative nausea-vomiting ( $\mathrm{P} \geq$ 0.05 ). However, a significant difference was observed between the three groups in terms of postoperative shivering with a higher frequency of shivering observed in placebo group $(\mathrm{P}=0.001)$. No significant difference was observed between tramadol and dexmedetomidine groups $(\mathrm{P} \geq 0.05)$. Patel et al. 
conducted a research to compare dexmedetomidine and midazolam in studying sedative factors and sensory, motor, and cardiovascular block and reduction of anesthetic medicines in spinal anesthesia. They arrived at the conclusion that Dexmedetomidine yields more postoperative analgesia and a longer period of sensory and motor block with minimum complications [6]. Their results are not in line with our research as no statistically significant difference was observed between Dexmedetomidine and tramadol in terms of length of analgesia. This difference can be attributed to the fact that Dexmedetomidine and Midazolam were used by Petal et al. and different levels of each medicine was used in these two researches. Zadeh et al. conducted a research on the effect of diclofenak and teramadol in pain after cesarean. The postdelivery analgesic period in tramadol group was significantly shorter than what was observed in diclofenak and a mixture of both medicines. Considering the acceptable length of postcaesarean analgesia, diclofenak that is a non-invasive, cheap, easy and complication less method is used instead of injected tramadol [7]. The results of Zadeh et al. [7] are not in line with the current research. The present research failed to find a significant difference between Dexmedetomidine and tramadol in terms of the length of post-delivery analgesia. This is probably because the types of medicines compared are different from tramadol. On the other hand, Zadeh et al. [7] had no placebo group and their research was conducted with a smaller sample size. A research by Yazdi et al. to study the effect of dexmedetomidine among sick children found Dexmedetomidine to be more effective than Midazolam as it enhances preoperative sedation and reduces postoperative pain. However, further research is required to assess dose designs and long terms side effects of dexmedetomidine in pediatric anesthesia [8].

These results are not in line with those achieved in our research. Dexmedetomidine and tramadol caused no difference in postoperative analgesia and this may be attributed to utilized doses and target group. The target group in Yazdi et al. consisted on children, while the target group in our research was women candidated for elective caesarean. In another research by Yazdi et al. better hemodynamic stability was achieved in patients with high blood pressure compared with Midazolam and anti-high blood pressure necessities were reduced [9]. The results of Yazdi et al. [9] are not in line with our research. In the present research, no difference was observed in hemodynamic changes between dexmedetomidine and Tramadol. The groups compared because Yazdi et al. [9] has compared dexmedetomidine with Midazolam, while our research has compared dexmedetomidine with tramadol probably cause this conflict. A randomized, double blind clinical trial conducted by Yang et al. to study the clinical effects of intramuscular Dexmedetomidine arrived at the conclusion that a low dose of dexmedetomidine $(1 \mu \mathrm{g} / \mathrm{kg})$ injected intramuscularly before the operation can act as a pain killer and induce auxiliary anesthesia effect without clinical Bradycardia or reduction of blood pressure [10]. This is in line with the results achieved in our research. Subedi et al. conducted a research to study the effect of intrathecal tramadol on patients undergoing caesarean. They finally arrived at the conclusion that adding tramadol and fentanyl as adjuvant to Bupivacaine in Subarachnoid block in caesarean reduces the length of analgesia and occurrence of shivering and tramadol is more effective [11]. The results of the research by Subedi et al. are not in line with the present research. This is probably due to using 25 milligrams tramadol with lidocaine $5 \%$ in the present research while Subedi et al. [11] used $10 \mathrm{~mL}$ intrathecal bupivacaine $0.5 \%$ with $10 \mathrm{~mL}$ tramadol. He also compared tramadol with fentanyl and had no placebo group.

In a study by Shahrokhi et al., with comparison the effect of intrathecal midazolam and tramadol on controlling postcaesarean shivering and pain, have shown that the average of postoperative pain score, shivering, and the analgesics in tramadol group was significantly less than the other two groups and it was less than control and midazolam groups $(\mathrm{P}<0.0001)$. They stated that using midazolam and tramadol as supplement medicine for lidocaine $5 \%$ in caesarean increases the period of postoperative analgesia and shivering where tramadol is more effective than midazolam [12]. These results are not in line with the present research. No significant difference was observed between the two groups in our research on terms of pain and shivering but both groups had a significant difference with placebo. This difference is probably due to different medicines used for comparison. We used tramadol and dexmedetomidine, while Shahrokhi et al compared tramadol with Midazolam.

In another study by Shukla et al. to compare the effect of Clonidine and tramadol in controlling shivering after spinal anesthesia, the total time required to completely remove shivering in Clonidine and tramadol group was $2.54 \pm 0.76$ and $5.01 \pm 1.02$ hours respectively. The response rate in clonidine and tramadol groups was 97.5 and $92.5 \%$ respectively [13]. Their results are not in line with the results achieved in this research and this is probably due to the difference in the dose of tramadol used by Shukla et al. [13] and their smaller sample size. Heid et al. have been suggested that the occurrence and intensity of shivering in tramadol group was less while no difference was observed between the tramadol and control group on terms of the pain score and hemodynamic variables [14]. Our findings showed that tramadol has a better performance than placebo group in controlling the pain in contrast with study of Heid et al. [14]. This difference can be attributed to the type of anesthesia in these studies. Therefore, we have been used spinal anesthesia compared to general anesthesia. However, their results are in agreement with the current study on the intensity of shivering.

Imani et al. conducted a research to study the effects of sensory and motor block of pregnant women, neonatals' Apgar and the side effects of adding 50 to 100 milligram tramadol to lidocaine $2 \%$ under epidural anesthesia in elective caesarean. According to the results yielded in the present research, adding tramadol to lidocaine $2 \%$ to achieve epidural anesthesia among pregnant women for caesarean has various advantages such as anesthesia during the operation and postoperative analgesia and does not increase maternal and neonatal complications 
[15]. These findings are in contrast with our results. Because we have been used spinal anesthesia than epidural anesthesia together with lidocaine $2 \%$ and the higher doses of tramadol. In another research by Kamali et al. it turned out that intrathecal addition midazolam and neostigmine to lidocaine $5 \%$ in spinal anesthesia could help enhance analgesia among patients under colporrhaphy. It turned out that midazolam was more effective than neostigmine in elongating the length of analgesia [16].

In conclusion, no significant difference was observed between dexmedetomidine and tramadol groups on terms of pain score, postoperative analgesic period, average amount of drug taken, nausea and vomiting and shivering after caesarean.

\section{Recommendations}

1. Various doses of Dexmedetomidine and tramadol must be used

2. Neonatal's Apgar must also be taken into consideration

\section{References}

1. Shahrokhi N, Pazuki S, Kamali A, Talebi H. Comparison between intrathecal midazolam and tramadol with conventional method for postoperative pain and shivering control after elective cesarean section. Anesthesiol Pain J 2013; 3: 76-72.

2. Stamer U, Schneck H, Grond S, Wulf H. Surveys on the use of regional anaesthesia in obstetrics. Curr Opin Anaesthiol 1999; 12: 565-571.

3. Ng k, Parsons J, Cyna A, Middleton P. Spinal versus epidural anaesthesia for caesarean section. Cochrane Database Syst Rev 2004; 2: CD003765.

4. Anaesthesiologists PgfoaarbtASo. Task force on obstetrical anaesthesia. Anesthesiol 1999; 90: 600-611.

5. Son A, Rudra A, Sarkar S, Biswas B. Intrathecal midazolam for postoperative pain relief in caesarean section delivery. J Indian Med Assoc 2001; 19: 683-686.

6. Fuhai J, Zhongmin L, Hung N, Nilas Y, Pengcai S, Neal F. Perioperative dexmedetomidine improves outcomes of cardiac surgery. Circulation 2013; 127: 1576-1584.

7. Zadeh LM, Zirak N, Ghomian N, Ebrahimi F, Zadeh MM. Effect of Diclofenak and Teramadol in pain afetr cesarean in spinal. IJOGI 2015; 17: 1-5.

8. Peng K, Wu SR, Ji FH, Li J. Premedication with dexmedetomidine in pediatric patients: a systematic review and meta-analysis. Clinics 2014 ; 69: 777-786.
9. Sezen G, Demiraran Y, Seker IS, Karagoz I, Iskender A, Ankarali H, Ersoy O, Ozlu O. Does premedication with dexmedetomidine provide perioperative hemodynamic stability in hypertensive patients? BMC Anesthesiol 2014; 14: 113.

10. Yang S, Chaolei L, Yuehong Z, Bin L, Shouzhang S, Lixin $X$. Low-dose intramuscular dexmedetomidine as premedication: A randomized controlled trial. Med Sci Monit 2014; 20: 2714-2719.

11. Subedi A, Biswas BK, Tripathi M, Bhattarai BK, Pokharel K. Analgesic effects of intrathecal tramadol in patients undergoing caesarean section: a randomised, double-blind study. Int J Obstetric Anesthesia 2013; 22: 316-221.

12. Pazuki SH, Kamali AR, Shahrokhi N , Jamilian M. Comparison of the effects of intrathecal midazolam and tramadol with the conventional method of postoperative pain and shivering control after elective cesarean section. Biomed Pharmacol J 2016; 9: 995-1003.

13. Shukla U, Malhotra K, Prabhakar T. A comparative study of the effect of clonidine and tramadol on post-spinal anaesthesia shivering. Indian J Anaesth 2011; 55: 242-246.

14. Heid F, Grimm U, Roth W, Piepho T, Kerz T, Jage J. Intraoperative tramadol reduces shivering but not pain after remifentanil-isoflurane general anaesthesia. A placebocontrolled, duouble-blind trial. Eur J Anaesthesiol 25: 468-472.

15. Imani F, Hassani V, Entezari S. Evaluation of maternal and neonatal effects of adding tramadol to $2 \%$ lidocaine in epidural anesthesia for cesarean section. Anesth Pain 2011; 1: 25-29.

16. Kamali A, Pazoki S, Shokrpour M, Vatanpour K. Comparison of effect of additive midazolam with neostigmine to lidocaine $5 \%$ in Post operation pain in colporrhaphy surgery in Spinal Anesthesia. Arak Med Univer J 2012; 15: 35-41.

\section{*Correspondence to}

Maryam Shokrpour

Department of Gynecology

Arak University of Medical Sciences

Iran 